\title{
KLAUS WÄHLER
}

\section{Interreligiöses Kollisionsrecht im Bereich privatrechtlicher Rechtsbeziehungen} Heymann, Berlin, 1978, XIV, 485 S., 120 DM

Die hier anzuzeigende überarbeitete Fassung der Berliner Habilitationsschrift Wählers aus dem Jahre 1972 bietet eine systematische Darstellung der Hauptfragen des interreligiösen Privatrechts. Der Schwerpunkt der Arbeit liegt in einer Bestandsaufnahme und kritischen Wertung der interreligiösen Normen (Kollisionsnormen) in religiösen Privatrechtsordnungen (Teil B). Dargestellt werden hier die kollisionsrechtlichen Maßstäbe, nach denen das Islamrecht, das Hindurecht, das jüdische Recht und die Rechte der christlichen Kirchen etwa Fragen der Zugehörigkeit zu einer Religionsgemeinschaft, des Verbots familiärer ,,Mischbeziehungen“, der Sanktionen beim ,,Abfall“" von Mitgliedern etc. behandeln. Ferner werden die Kriterien für dieStatuierung der eigenen Anwendbarkeit auf Andersgläubige und der Maßgeblichkeit anderer staatlicher oder religiöser Rechte erörtert. Daran anschließend (Teil C) folgt ein Uberblick über die interreligiösen Kollisionsnormen in staatlichen Rechten (d. h. der Konfliktsregelungen in Staaten mit mehreren, nebeneinander geltenden religiösen Teilrechtsordnungen). - Das Buch behandelt damit einen Gegenstand, dessen Bedeutung für Theorie und Praxis der Rechtsvergleichung und des Kollisionsrechts kurzzeitig nurmehr eine historische gewesen sein mag; heute ist das interreligiöse Kollisionsrecht indessen fraglos eine hochmoderne Disziplin: Mit dem Erwerb der Unabhängigkeit lösten sich viele der neuentstandenen Staaten Asiens und Afrikas auch aus den Banden der rechtlichen Uniformierung, in die sie von den europäischen Kolonialmächten - teilweise mit dramatischen sozialen Konsequenzen ${ }^{1}$ - gelegt worden waren. Dort, wo die gewachsenen Rechtsstrukturen innerhalb der verschiedenen ethnischen und religiösen Gruppen nicht durch den Kolonialherrn respektiert und allenfalls in Teilbereichen kodifikatorisch erfaßt worden waren ${ }^{2}$, erlangten sie ihren prägenden Einfluß of tmals außerordentlich rasch zurück. Namentlich die nicht primär von Leistungsaustausch und Kapitalverwertung bestimmten Gebiete des Familien- und Erbrechts standen bald weitgehend wieder im Zeichen der überkommenen Rechtstraditionen. Unmittelbare Folge dieser Entwicklung ist die weltweite Zunahme der Mehrrechtssysteme. Hierauf muß sich die Praxis der Gerichte einstellen, wenn sie Sachverhalte beurteilen will, die Berührungspunkte mit solchen Systemen haben und deshalb einen Verweis des eigenen Internationalen Privatrechts auf ,,das“ Recht eines Mehrrechtsstaates auslösen. Wegen der unablässig größer werdenden Zahl derartiger Fälle gerade im Bereich des Familienrechts ${ }^{3}$ ist Wählers Schrift nicht nur als grundlegender und umfassender Beitrag zur Theorie der unterstaatlichen Kollisionsrechte (interlokales, interpersonales, interreligiöses Privatrecht) von Interesse ${ }^{4}$; sie wird auch dem Praktiker eine Fülle von Hinweisen für die richtige Bewältigung komplizierter Auslandssachverhalte liefern, die mehrstufige kollisionsrechtliche Uberlegungen erforderlich machen. Darüber hinaus enthält das Werk zahllose detaillierte Informationen zum materiellen Inhalt von Normen aus den behandelten Rechtsordnungen. Es trägt dadurch nicht nur zum sicheren Umschiffen auch der zweiten

\footnotetext{
1 Man denke nur etwa an die Einführung des familienrechtlichen Konzeptes der „Nichtehelichkeit“ durch die Briten in westafrikanischen Gesellschaften, denen dergleichen völlig unbekannt war.

2 Ein Beispiel ist die Fortgeltung des Adatrechts bei Kodifikation bestimmter Materien im Recht der Chinesen und anderer ethnischer Gruppen unter der niederländischen Herrschaft in Indonesien.

3 Vgl. zum Adoptionsrecht die Beiträge von Magnus/Münzel, St AZ 1977, S. 65 ff. (allgemein Ưbersee); Magnus, StAZ 1977 , S. 248 ff. (Indien); Kronke, StAZ 1977, S. 151 ff. (Indonesien).

4 Vgl. hierzu Neuhaus, Die Grundbegriffe des Internationalen Privatrechts, 2. Aufl. 1976, S. 306 ff.; Wengler, Rec. des Cours 104 (1961 - III), S. 273, 289 ff.; Richter, Die Rechtsspaltung im malaysischen Familienrecht, 1976.
} 
Klippe in einem Auslandssachverhalt - dem Auffinden und der korrekten Auslegung der ,,rule of decision“ - bei, sondern wird sich als Fundgrube für manches weitgreifende rechtsvergleichende Forschungsvorhaben erweisen.

Herbert Kronke

\section{Hilmar KRUger}

Fetwa und Siyar

Harrassowitz Verlag, Wiesbaden 1978, 190 S., DM 58,-

Der Verfasser beschäftigt sich mit Fragen internationalrechtlichen Charakters; dieser Begriff ist jedoch nicht als terminus technicus zu verstehen, sondern soll allgemein Rechtsprobleme mit Auslandsbezug beinhalten - so werden staatsrechtliche, staatsangehörigkeitsrechtliche, völker-, fremden- und kollisionsrechtliche Fragen erörtert. Der Abhandlung sind Sammlungen osmanischer Rechtsgutachten (fetawa) aus der Zeit vom 17. bis zum 19. Jh. zugrunde gelegt. Zur Einführung des Lesers werden der rechtsgeschichtliche Hintergrund und Parallelen bei der Praxis der Erstellung von Rechtsgutachten in anderen Rechtskreisen (so im jüdischen und im römischen Recht) aufgezeigt.

Die Kürze der Darstellung gibt dem Werk einen grundrißartigen Charakter, wesentliche, zur Vertiefung führende Probleme sind aus den sehr ausführlichen Anmerkungen ersichtlich. Die Transliteration mancher hocharabischer oder türkischer Worte ist selbst auf einer Textseite nicht einheitlich, der Sachtext nicht immer fehlerlos verlesen. Die unterschiedlichen Funktionen eines muftî und eines 'ulamä' sind nicht klar abgegrenzt. Die Bedeutung der Rechtsgutachten nach der ,,Schließung des Tores des igtihād“ für die Rechtsfortentwicklung wird m. E. nicht einhellig in Ubereinstimmung mit der Auffassung des Verfassers gesehen ${ }^{1}$. Der Begriff waqf ist wohl auch nicht einfach als Stiftung zu übersetzen, sondern spez. als fromme Stiftung bzw. als Stiftung für einen frommen oder wohltätigen Zweck ${ }^{2}$.

Abgesehen von diesen Ungenauigkeiten ist es dem Verfasser gelungen, einen aufschlußreichen Uberblick über die wichtigsten fetwa-Sammlungen zu bringen und die vitae ihrer Verfasser anzugeben. Der Einfluß des saih al-islām auf die Rechtsentwicklung und damit mittelbar auf die Gestaltung des sozialen Lebens ist bis zum 19./20. Jh. bedeutend gewesen; herausragende Ereignisse sind die Abschaffung des Brudermordgesetzes durch Ali Efendi im 17. Jh. und die Einführung des Buchdrucks durch Abdullah Efendi zu Beginn des 18. Jh. Nach der Schilderung des Aufbaus der fetwa-Werke behandelt der Verfasser ausschnittweise, d. h. soweit in den benutzten fetwa-Sammlungen enthalten, die eingangs erwähnten internationalrechtlichen Fragen. Err weist auf besondere staatsrechtliche Probleme hin, so die Legitimität des Kalifats osmanischer Sultane, die nicht zum Stamme der Qurais zählen, und greift bei staatsangehörigkeitsrechtlichen Fragen, die im europäischen Rechtsverständnis erst ab 1869 im osmanischen Rechtsdenken auftreten können, bereits die Zweiteilung in dār al-harb - dār al-islām auf, die in dieser Form auch der Lösung fremdenrechtlicher und kollisionsrechtlicher Fragenkreise zugrunde gelegt werden muß. Im Rahmen völkerrechtlicher Themen untersucht der Verfasser die Beziehungen islamischer zu nichtislamischen Staaten und islamischer Staaten untereinander. Der zuletzt genannte Fragenkreis hat heute nur noch rechtshistorische Bedeutung, bis 1856 - dem Ende des Krim-Krieges - verschloß sich das Osmanische Reich den Normen des Völkerrechts. Alle islamischen Staaten gehörten zu dem

1 Wie der Verf.: Schacht, Law, and Justice, The Cambridge History of Islam, Bd. 2,564; a. M. Gardet, Der Islam, 157.

2 Fyzee, Outlines of Muhammadan Law, 3. Auflg., 271; Wehr, Arabisches Wörterbuch für die Schriftsprache der Gegenwart, 971. 